\title{
Evaluation of Size of Ventricles of Human Brain using Magnetic Resonance Imaging Technique
}

\author{
Deewakar Poudel, ${ }^{1}$ Hari Prasad Lamichhane ${ }^{1 *}$, Sharma Paudel, ${ }^{2}$ and Ram Bahadur Chand ${ }^{2}$ \\ ${ }^{1}$ Central Department of Physics, Tribhuvan University, Kirtipur, Kathmandu, Nepal \\ ${ }^{2}$ Department of Radiology and Imaging, Tribhuvan University Teaching Hospital, Kathmandu, Nepal \\ *Email: hlamichhane1@gmail.com
}

\begin{abstract}
The prospective cross-sectional study of human brain was conducted to establish the range of size of ventricular system in normal human brain of Nepalese population (irrespective of race) by using magnetic resonance imaging (MRI) at Institute of Medicine, Department of Radiology and Imaging, Tribhuvan University Teaching Hospital (TUTH) on 150 subjects ( 75 male and 75 female) of age between 10 - 80 years with 0.3 Tesla static magnetic field. The bifrontal diameter, bihemispheric diameter, frontal horn ratio, transverse dimension of third ventricle, anterior - posterior dimension and width of fourth ventricle were observed to be $32.7 \mathrm{~mm}$ and $31.0 \mathrm{~mm}, 105.1 \mathrm{~mm}$ and $101.2 \mathrm{~mm}, 0.31$ and $0.31,4.7 \mathrm{~mm}$ and $4.4 \mathrm{~mm}, 9.9 \mathrm{~mm}$ and $9.4 \mathrm{~mm}, 12.3 \mathrm{~mm}$ and $11.7 \mathrm{~mm}$ in case of male and female respectively with overall average of $31.9 \mathrm{~mm}, 103.1 \mathrm{~mm}, 0.31,4.6 \mathrm{~mm}, 9.7 \mathrm{~mm}$, and $12.0 \mathrm{~mm}$ respectively. The measurement of ventricular dimension was observed to be statistically significant between male and female except transverse dimension of third ventricle and was greater in male than in female in all cases.
\end{abstract}

Keywords: Brain, Brain ventricles, Magnetic resonance imaging, Ventricular size

\section{INTRODUCTION}

Magnetic resonance imaging provides acquisition of 3-dimensional data and measurement of linear distance in any chosen image plane using appropriate software. The advantages given by the modern imaging methods and minimally invasive technique motivated many researchers to study the anatomy of ventricular system and measure the distances in individuals (Duffner et al. 2003). Further, MR image data set can be used for the design of instruments for minimally invasive neurosurgery (Riegel et al. 2002).

Understanding the normal and abnormal anatomy of the ventricular system of the brain is helpful for clinician, neurosurgeon and radiologist in day-to-day practices. The abnormal anatomy of lateral ventricle may be great academic interest regarding cerebrospinal fluid circulation and also important for surgical intervention (Srijit \& Shipra 2006). Morphometric analysis of cerebral ventricular system is important for evaluating changes due to growth, ageing, intrinsic and extrinsic pathology (Aziz et al. 2004). Neurologist are frequently faced with the problems of deciding whether the ventricles are within the normal limits or enlarged with patient's age.

It is necessary to define normal range with a uniform, comparable and exact method of measuring ventricular size (Haug 1977). Morphometric analysis of brain structure such as volume, shape and size of ventricular system specially lateral ventricle, recently become a main focus of interest in studies of some neurophychiatric diseases like Alzheimer's (Ashtari et al. 1990). Further, the knowledge of the measurement of ventricular system of brain by MRI is of use in diagnosis of some diseases like hydrocephalus, schizophrenia and surgical intervention like endoscopic neurosurgery (Satapara et al. 2014). The cerebral ventricles are of a relatively fixed size and shape and in the absence of the diseases, do not vary significantly and systematic study is desirable to establish this point (Evans 1942). To understand these changes the knowledge of normal morphometry and size of normal ventricular system of brain is important. The objective of the study was to establish the range of the size of ventricular system in normal brain MRI and compute frontal horn ratio of healthy Nepalese people.

\section{MATERIALS AND METHODS}

The prospective cross-sectional study was conducted at Institute of Medicine, Department of Radiology and Imaging, Tribhuvan University Teaching Hospital (TUTH) on 150 subjects ( 75 male and 75 female) of age between $10-80$ years. The MRI were randomly selected 
which were reported normal by radiologist. The brains MRI were included in this study if they were Nepalese and participants aged between 10-80 years as well as provided an oral consent. Also brain MRI were excluded in this study if they were described as abnormal with evidence of space occupying lesions, cerebral hemorrhage, brain tumor, head injuries and previous intracranial surgeries.

The measurements were made using Airis Vento [Hitachi Incorporation] MRI machine with 0.3 Tesla magnetic field facilitated with computer program Dicom Viewer. The MRI measurements on the brain ventricle were done in spin-echo sequence, $T_{2}$-axial slice with thickness of $6 \mathrm{~mm}$ having repetition time (TR)/echo time (TE) of $4500 / 100$ milliseconds and was calibrated to $0.1 \mathrm{~mm}$. The patient was placed on MRI table with head centered at the brain coil. The ethical clearance was sought from and approved by Research Department, Institutional Review Board, TUTH and oral consent was taken from patient for the use of their result in the study.

The following measurements were made from the MRI images which are obtained by the standard protocol made by the radiological society.

- Measurement of bifrontal diameter:

The maximum bifrontal diameter is the transverse distance defined by a line connecting two anterior corners of the frontal horns $\mathrm{a}$ and $\mathrm{b}$ (Fig. 1).

- Measurement of bihemispheric diameter:

The brain width or bihemispheric diameter is the distance measured along the line of bifrontal diameter to the brain edge $\mathrm{c}$ and d (Fig. 2).

- Calculation of frontal horn ratio (FHR):

Frontal horn ratio is the greatest distance between the tip of the frontal horn divided by the first transverse diameter of the brain along the same level.

Frontal horn ratio:- Bifrontal diameter/ bihemispheric diameter

- Measurement of transverse dimension of third ventricle:
The transverse dimension of third ventricle is the greatest distance between lateral margin of the third ventricle from e to f (Fig. 3).

- Measurement of anterior-posterior dimension and width of fourth ventricle:

The greatest anterior-posterior dimension of fourth ventricle is the distance from anterior aspect of vermis to the posterior aspect of pons, a line connecting $i$ and $j$ and the width is the maximum transverse distance along the coronal plane connecting $g$ and $h$ (Fig. 4).

\section{RESULTS}

\section{Measurements based on age group combined}

The data collected from the experimental MRI images of brain ventricle of Nepalese subjects (included in this research) were statistically interpreted with some statistical tools and the results were observed statistically significant. Because of the time limitation of observation and experimental difficulties for age variation of ventricle size, data were taken from different subjects with different ages instead from the single subject at different ages. The mean, standard deviation (S.D.), mean deviation (M.D.), confidence interval (CI) for lower (L) and upper (U) bound, minimum and maximum values were calculated.

Table 1 shows that the measured bifrontal diameter was almost equal in all age groups with slight variation and also similar results were observed in case of bihemispheric diameter. The maximum and minimum values were observed at second and eighth decade of life for both cases. The frontal horn ratio seems somewhat equal in all age groups with slightly higher value at seventh decade.

It can be summarized that the mean values in case of transverse dimension of third ventricle were slightly increasing in order from fourth decade of life to seventh decade of life. The anterior-posterior dimension and width of fourth ventricle was observed to be same at different age groups with quite low value at sixth decade of life in case of width. 


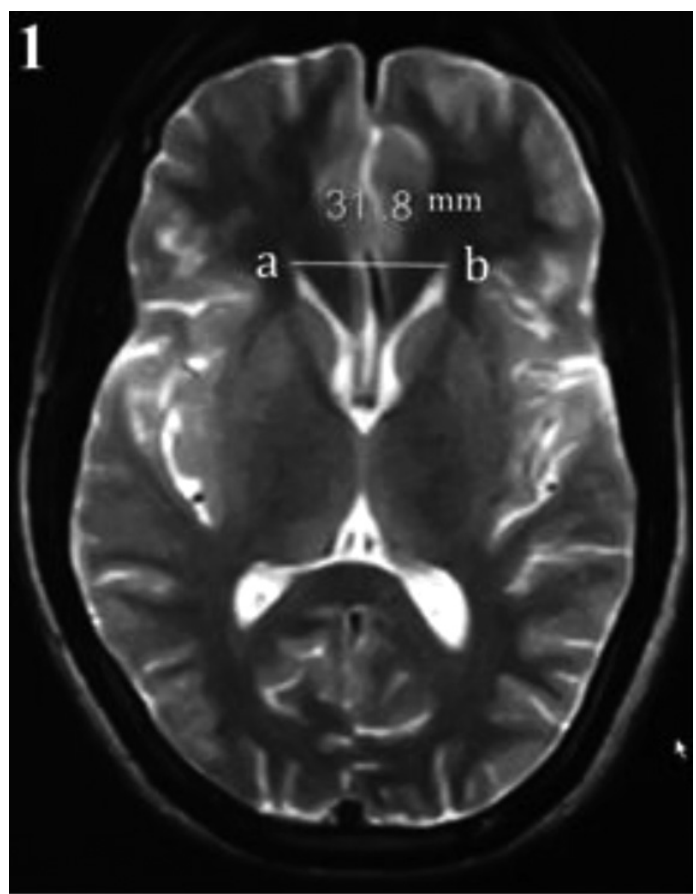

Fig. 1. MRI scan of brain showing transverse diameter of frontal horn (a-b) defined by the line connecting the two anterior corners of frontal horn

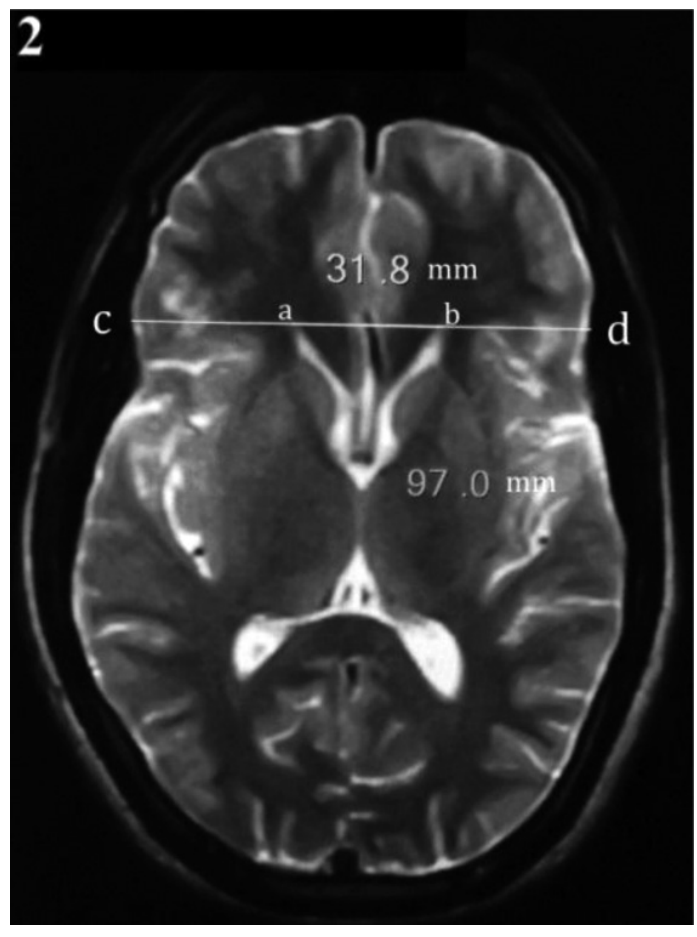

Fig. 2. MRI scan of brain width or bihemis-pheric diameter (c-d) along the bifrontal diameter (a-b)

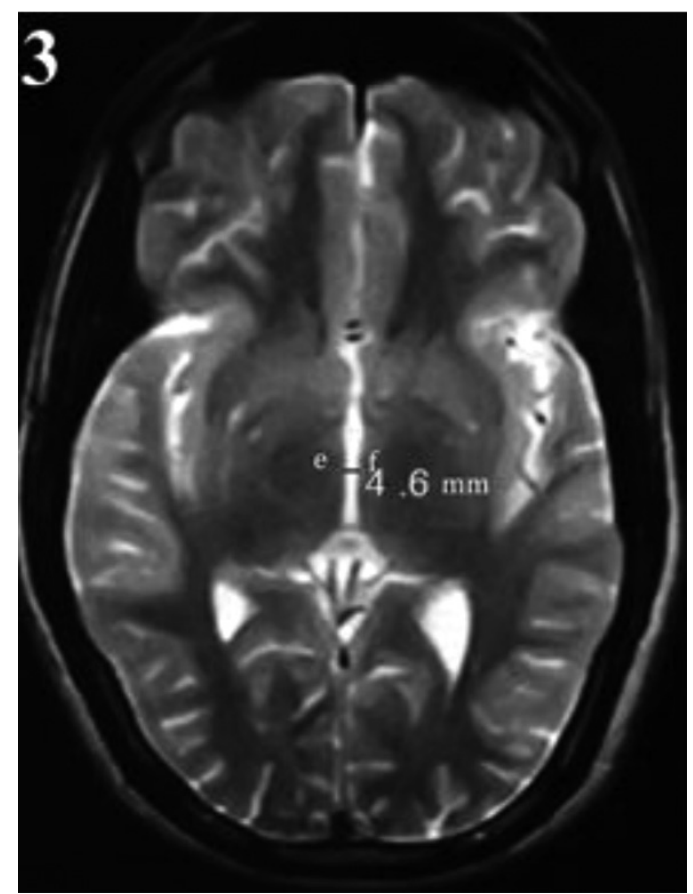

Fig. 3. MRI scan of third ventricle showing greatest transverse diameter (e-f) along coronal plane

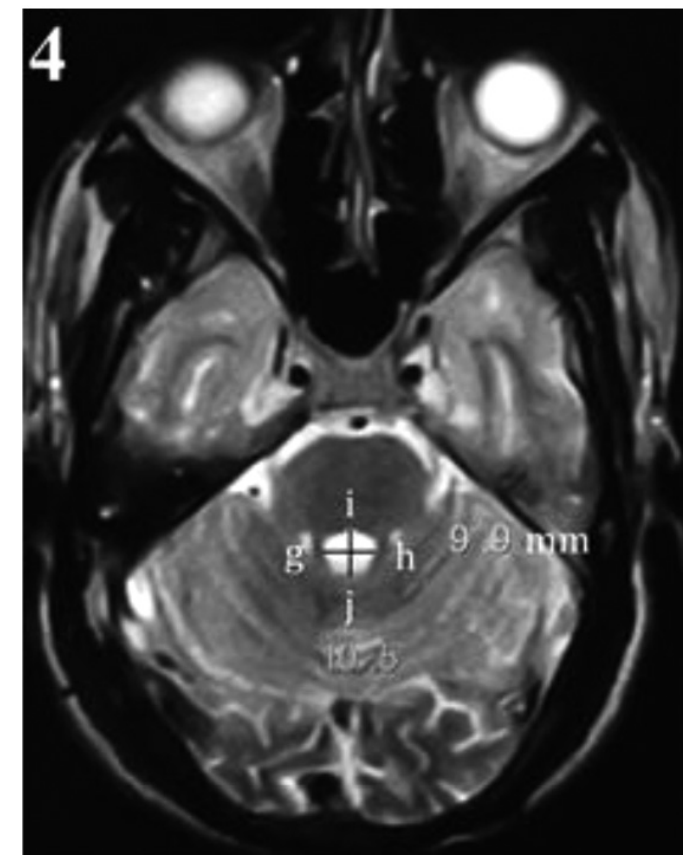

Fig. 4. MRI scan of fourth ventricle showing greatest vertical diameter (i-j) and greatest transverse diameter ( $g$ h) along coronal plane 
Table 1. Measurement made on the bifrontal diameter (BFD), bihemispheric diameter (BHD), frontal horn ratio (FHR), third ventricle transverse dimension (TVTD), fourth ventricle anterior - posterior dimension (FVAP) and fourth ventricle width (FVW) of 150 normal brain MRI at different age groups for both gender combined

\begin{tabular}{|c|c|c|c|c|c|c|c|c|c|}
\hline $\mathrm{Mm}$ & Age & Mean & S.D. & M.D. & $95 \% \mathrm{CI} \quad(\mathrm{L})$ & $95 \%$ CI (U) & Min. & Max. & $\mathrm{N}$ \\
\hline \multirow{7}{*}{$\begin{array}{l}\text { BFD } \\
(\mathrm{mm})\end{array}$} & $10-19$ & 32.5 & 2.6 & 2.0 & 31.4 & 33.6 & 27.9 & 37.8 & 25 \\
\hline & $20-29$ & 31.8 & 2.3 & 1.8 & 31.0 & 32.7 & 27.2 & 36.8 & 32 \\
\hline & $30-39$ & 31.2 & 1.9 & 1.3 & 30.4 & 32.1 & 26.1 & 34.8 & 21 \\
\hline & $40-49$ & 32.2 & 2.1 & 1.8 & 31.1 & 33.2 & 29.0 & 35.9 & 19 \\
\hline & $50-59$ & 31.6 & 2.1 & 1.6 & 30.8 & 32.5 & 26.3 & 35.4 & 25 \\
\hline & $60-69$ & 32.4 & 2.8 & 2.5 & 30.9 & 33.9 & 27.7 & 36.4 & 16 \\
\hline & $70-79$ & 31.0 & 2.5 & 1.6 & 32.6 & 32.6 & 24.3 & 34.3 & 12 \\
\hline \multirow{7}{*}{$\begin{array}{l}\text { BHD } \\
(\mathrm{mm})\end{array}$} & $10-19$ & 104.4 & 5.0 & 4.0 & 102.5 & 106.7 & 92.5 & 114.2 & 25 \\
\hline & $20-29$ & 102.8 & 5.2 & 4.2 & 101.0 & 104.7 & 92.1 & 113.3 & 32 \\
\hline & $30-39$ & 102.2 & 3.8 & 3.1 & 100.5 & 104.0 & 93.8 & 110.8 & 21 \\
\hline & $40-49$ & 103.9 & 5.3 & 4.0 & 101.3 & 106.4 & 94.6 & 114.8 & 19 \\
\hline & $50-59$ & 104.1 & 6.0 & 4.5 & 101.6 & 106.6 & 90.3 & 117.1 & 25 \\
\hline & $60-69$ & 102.8 & 6.5 & 5.2 & 99.3 & 106.3 & 89.0 & 115.0 & 16 \\
\hline & $70-79$ & 99.8 & 3.2 & 2.6 & 97.7 & 101.8 & 95.7 & 105.2 & 12 \\
\hline \multirow[t]{7}{*}{ FHR } & $10-19$ & 0.31 & 0.02 & 0.02 & 0.30 & 0.32 & 0.26 & 0.35 & 25 \\
\hline & $20-29$ & 0.30 & 0.02 & 0.01 & 0.30 & 0.31 & 0.28 & 0.35 & 32 \\
\hline & $30-39$ & 0.30 & 0.01 & 0.01 & 0.30 & 0.31 & 0.28 & 0.33 & 21 \\
\hline & $40-49$ & 0.31 & 0.02 & 0.01 & 0.30 & 0.32 & 0.28 & 0.34 & 19 \\
\hline & $50-59$ & 0.30 & 0.02 & 0.02 & 0.30 & 0.31 & 0.27 & 0.35 & 25 \\
\hline & $60-69$ & 0.32 & 0.02 & 0.02 & 0.31 & 0.33 & 0.26 & 0.35 & 16 \\
\hline & $70-79$ & 0.31 & 0.02 & 0.02 & 0.30 & 0.33 & 0.25 & 0.34 & 12 \\
\hline \multirow{7}{*}{$\begin{array}{l}\text { TVTD } \\
(\mathrm{mm})\end{array}$} & $10-19$ & 4.4 & 1.0 & 0.8 & 4.0 & 4.8 & 2.4 & 6.3 & 25 \\
\hline & $20-29$ & 4.2 & 1.0 & 0.9 & 3.8 & 4.6 & 2.8 & 6.6 & 32 \\
\hline & $30-39$ & 4.1 & 0.8 & 0.7 & 3.7 & 4.5 & 3.0 & 5.4 & 21 \\
\hline & $40-49$ & 4.8 & 0.8 & 0.7 & 4.4 & 5.2 & 3.2 & 6.2 & 19 \\
\hline & $50-59$ & 4.9 & 0.9 & 0.8 & 4.5 & 5.3 & 3.4 & 6.5 & 25 \\
\hline & $60-69$ & 5.0 & 1.0 & 0.8 & 4.5 & 5.3 & 3.1 & 6.3 & 16 \\
\hline & $70-79$ & 4.8 & 0.9 & 0.8 & 4.3 & 5.4 & 3.5 & 6.1 & 12 \\
\hline \multirow{7}{*}{$\begin{array}{l}\text { FVAP } \\
(\mathrm{mm})\end{array}$} & $10-19$ & 9.4 & 1.1 & 0.8 & 9.0 & 9.9 & 7.3 & 12.4 & 25 \\
\hline & $20-29$ & 9.5 & 1.0 & 0.7 & 9.2 & 9.9 & 8.0 & 11.4 & 32 \\
\hline & $30-39$ & 9.8 & 1.5 & 1.2 & 9.2 & 10.5 & 7.7 & 12.7 & 21 \\
\hline & $40-49$ & 9.8 & 1.2 & 1.0 & 9.2 & 10.4 & 8.0 & 12.3 & 19 \\
\hline & $50-59$ & 9.9 & 1.0 & 0.7 & 9.5 & 10.3 & 7.7 & 12.8 & 25 \\
\hline & $60-69$ & 9.8 & 0.9 & 0.8 & 9.3 & 10.3 & 8.5 & 11.5 & 16 \\
\hline & $70-79$ & 9.4 & 1.5 & 1.7 & 8.4 & 10.3 & 7.5 & 12.2 & 12 \\
\hline \multirow{7}{*}{$\begin{array}{l}\text { FVW } \\
(\mathrm{mm})\end{array}$} & $10-19$ & 12.0 & 1.5 & 1.3 & 11.4 & 12.6 & 9.3 & 14.5 & 25 \\
\hline & $20-29$ & 12.1 & 1.1 & 0.9 & 11.7 & 12.5 & 10.3 & 14.4 & 32 \\
\hline & $30-39$ & 12.2 & 1.2 & 0.9 & 11.7 & 12.8 & 9.3 & 14.3 & 21 \\
\hline & $40-49$ & 11.9 & 1.6 & 1.3 & 11.2 & 12.7 & 9.8 & 14.5 & 19 \\
\hline & $50-59$ & 11.6 & 1.3 & 1.1 & 11.1 & 12.1 & 9.6 & 14.0 & 25 \\
\hline & $60-69$ & 12.1 & 1.0 & 0.9 & 11.6 & 12.7 & 10.6 & 13.7 & 16 \\
\hline & $70-79$ & 12.9 & 0.8 & 0.7 & 11.7 & 12.7 & 10.8 & 13.0 & 12 \\
\hline
\end{tabular}

\section{Measurements based on gender}

As seen in the Table 2, the mean bifrontal diameter was observed larger in males $(32.7 \pm 2.3) \mathrm{mm}, 95 \% \mathrm{CI}(32.2$ - 33.2) as compared to female $(31.0 \pm 2.1) \mathrm{mm}, 95 \%$ CI $(30.5-31.5)$ which was statistically significant $(\mathrm{z}=4.86>1.96)$. 
Similarly, mean bihemispheric diameter was observed to be larger in male $(105.1 \pm 5.0) \mathrm{mm}, 95 \% \mathrm{CI}(104.0-$ 106.3) than compared to female (101.2 \pm 4.7$) \mathrm{mm}, 95 \%$ CI (100.1 - 102.2) which was statistically significant $(\mathrm{z}=$ $4.88>1.96)$. The bifrontal diameter was observed to be $31.1 \%$ and $30.6 \%$ of bihemispheric diameter in case of male and female respectively.

The Table 3 shows the mean transverse dimension (width) of the third ventricle for male $(4.7 \pm 1.0) \mathrm{mm}, 95 \% \mathrm{CI}(4.5$ - 5.0) generally had non - significant tendency of larger mean width compared to female $(4.4 \pm 1.1) \mathrm{mm}, 95 \% \mathrm{CI}$ (4.2 - 4.6). Hence, there was no statistically significant difference between mean width of third ventricle in male and female $(\mathrm{z}=1.76<1.96)$.
Also, Table 3 shows the higher value of anterior - posterior dimension and width of fourth ventricle in male than in female. The mean anterior - posterior dimension or height of fourth ventricle of male and female was observed to be $(9.9 \pm 1.1) \mathrm{mm}, 95 \% \mathrm{CI}(9.6-10.1)$ and $(9.4 \pm 1.1)$ $\mathrm{mm}, 95 \%$ CI $(9.2$ - 9.7) respectively. Similarly, mean transverse dimension or width of fourth ventricle of male and female was $(12.3 \pm 1.2) \mathrm{mm}, 95 \% \mathrm{CI}(12.0$ - 12.6) and $(11.7 \pm 1.2) \mathrm{mm}, 95 \% \mathrm{CI}(11.4-12.0)$ respectively. Further, $\mathrm{z}=2.5>1.96$ for anterior - posterior dimension and $z=3.0>1.96$ for transverse dimension (width).

Hence, the sample provides the sufficient evidence that there was statistically significant difference between the mean for anterior - posterior dimension and width in case of male and female.

Table 2. Measurement and comparison of bifrontal diameter (BFD), bihemispheric diameter (BHD) and their frontal horn ratio (FHR) based on gender

\begin{tabular}{|c|c|c|c|c|c|c|}
\hline \multirow{2}{*}{ Statistics } & \multicolumn{2}{|c|}{ BFD (mm) } & \multicolumn{2}{|c|}{$\mathrm{BHD}(\mathrm{mm})$} & \multicolumn{2}{|c|}{ FHR } \\
\hline & Male & Female & Male & Female & Male & Female \\
\hline Mean & 32.7 & 31.0 & 105.1 & 102.2 & 0.31 & 0.31 \\
\hline S.D. & 2.3 & 2.1 & 5.0 & 4.7 & 0.02 & 0.02 \\
\hline M.D. & 1.9 & 1.5 & 3.8 & 3.8 & 0.02 & 0.01 \\
\hline 95\% CI (Lower) & 32.2 & 30.5 & 104.0 & 100.1 & 0.31 & 0.30 \\
\hline 95\% CI (Upper) & 33.2 & 31.5 & 106.3 & 102.2 & 0.32 & 0.31 \\
\hline Minimum & 27.7 & 24.3 & 93.0 & 89.0 & 0.26 & 0.25 \\
\hline Maximum & 37.8 & 35.4 & 117.1 & 110.2 & 0.35 & 0.35 \\
\hline Subjects & 75 & 75 & 75 & 75 & 75 & 75 \\
\hline
\end{tabular}

Table 3. Measurement and comparison of third ventricle transverse dimension (TVTD), fourth ventricle anterior - posterior dimension (FVAP) and fourth ventricle width (FVW) based on gender

\begin{tabular}{|c|c|c|c|c|c|c|}
\hline \multirow{2}{*}{ Statistics } & \multicolumn{2}{|c|}{ TVTD $(\mathrm{mm})$} & \multicolumn{2}{|c|}{ FVAP (mm) } & \multicolumn{2}{|c|}{ FVW (mm) } \\
\hline & Male & Female & Male & Female & Male & Female \\
\hline Mean & 4.7 & 4.4 & 9.9 & 9.4 & 12.3 & 11.7 \\
\hline S.D. & 1.0 & 1.1 & 1.1 & 1.1 & 1.2 & 1.2 \\
\hline M.D. & 0.8 & 0.8 & 0.9 & 0.8 & 1.0 & 1.0 \\
\hline 95\% CI (Lower) & 4.5 & 4.2 & 9.6 & 9.2 & 12.0 & 11.4 \\
\hline 95\% CI (Upper) & 5.0 & 4.6 & 10.1 & 9.7 & 12.6 & 12.0 \\
\hline Minimum & 3.0 & 2.4 & 8.0 & 7.3 & 10.0 & 9.3 \\
\hline Maximum & 6.6 & 6.5 & 12.8 & 12.5 & 14.5 & 14.5 \\
\hline Subjects & 75 & 75 & 75 & 75 & 75 & 75 \\
\hline
\end{tabular}

\section{Measurements based on all subjects}

The Table 4 summarizes the overall measurements made on the ventricles of 150 normal brain MRI scan of both gender combined. The bifrontal diameter was observed to be $30.9 \%$ of bihemispheric diameter. 
Table 4. Overall measurements made on the 150 normal brain MRI scan

\begin{tabular}{|l|c|c|c|c|c|c|}
\hline \multirow{2}{*}{ Statistics } & BFD & BHD & FHR & TVTD & FVAP & FVW \\
\cline { 2 - 7 } & $(\mathrm{mm})$ & $(\mathrm{mm})$ & & $(\mathrm{mm})$ & $(\mathrm{mm})$ & $(\mathrm{mm})$ \\
\hline Mean & 31.9 & 103.1 & 0.31 & 4.6 & 9.7 & 12.0 \\
\hline S.D. & 2.4 & 5.2 & 0.02 & 1.0 & 1.1 & 1.3 \\
\hline M.D. & 1.8 & 4.2 & 0.02 & 0.8 & 0.9 & 1.2 \\
\hline 95\% CI (L) & 31.5 & 102.3 & 0.30 & 4.4 & 9.5 & 11.8 \\
\hline 95\% CI (U) & 32.2 & 104.0 & 0.31 & 4.7 & 9.8 & 12.2 \\
\hline Minimum & 24.3 & 89.0 & 0.25 & 2.4 & 7.3 & 9.3 \\
\hline Maximum & 37.8 & 117.1 & 0.35 & 6.6 & 12.8 & 14.5 \\
\hline Subjects & 150 & 150 & 150 & 150 & 150 & 150 \\
\hline
\end{tabular}

[Here Mm., M, F, S.D., M.D., CI, CT, Min., Max., Nand mm represents Measurements, Male, Female, Standard Deviation, Mean Deviation, Confidence Interval for Upper (U) and Lower (L) bound, Computed Tomography, Minimum value, Maximum value, Number of subjects and millimeter respectively.]

\section{DISCUSSION}

The structure of human brain is the most complex, widely investigated and yet not fully understood physical system known to mankind. Characteristics structural changes of the human brain with age are considered to be normal and expected. The knowledge of the age related normal changes that occurs in brain is required before any abnormal finding analyzed. As ageing advances, brain undergoes many gross and histopathological changes with regression of brain tissues leading to the enlargement of the ventricle (Schochet 1998). The ventricular size changes in brain occurred in routine clinical practice which can mislead to most of the physician and surgeons to take proper decision. However, there is likely to be an increasing number of circumstances in which precise measurements will be needed (Roberts \& Caird 1976). In every measurement of brain ventricles of overall subjects, dimension appeared to be larger in male than in female. The adult human brain has the size of around $1130 \mathrm{~cm}^{3}$ in women and $1260 \mathrm{~cm}^{3}$ in men. Male brains are about 10 $\%$ larger than female brains in volume and weighs $11-12$ $\%$ more than that of female (Zaidi 2010). As anticipated to the cranial capacities (skull size) of male and female, we also observed similar relationships between male and female ventricle sizes.

\section{Frontal horn ratio}

Table 5. Comparison of frontal horn ratio with previous study

\begin{tabular}{|l|c|c|c|c|c|}
\hline Worker & Method & Subjects & Gender & Mean & S.D. \\
\hline Hahn & CT & 200 & M/F & 0.31 & 0.04 \\
\hline Park & CT & 1000 & M/F & 0.30 & 0.04 \\
\hline Cala & CT & 93 & M/F & $0.33 / 0.31$ & $0.06 / 0.08$ \\
\hline Soininem & CT & 85 & M/F & 0.32 & 0.04 \\
\hline Present & MRI & 150 & M/F & 0.31 & 0.02 \\
\hline
\end{tabular}

Considering the race, region and size, people can be divided as Asians, Europeans and Africans. A study related to various categories of about 20,000 skulls conducted by Rushton and Ankey (1996) found that Asian-descended people (Orientals), Europeansdescended people (Whites) and African descended people (Blacks) have cranial capacities of $1364 \mathrm{~cm}^{3}$, $1347 \mathrm{~cm}^{3}$ and $1267 \mathrm{~cm}^{3}$ respectively. Many other studies were conducted based on brain size and race differences found different values on cranial capacities. Therefore, to collect the average brain ventricle size, it is equally important to consider the ethnicity, geographical regions or locality and also nutritional factors. The present study demonstrated simple measurements can be made on the magnetic resonance imaging to establish the size of ventricular system. As expected, the size of ventricles of Nepalese subjects were different from people of other regions because other studies were done at different circumstances at various geographical regions with different races having dissimilar physical structure and brain size which were not matched with Nepalese population size. However, frontal horn ratio, transverse dimension of third ventricle and width of fourth ventricle were observed to be similar with some studies whereas anterior-posterior dimension seems slightly different from other studies. 
According to the Hahn and Rim (1976) the cerebroventricular index (frontal horn index) seems to be a reliable indicator of ventricular size and emphasizes the study of normal ventricles. The present study found the frontal horn ratio at the level of tips of frontal horn varied from minimum value of 0.25 to a maximum value of 0.35 averaging $(0.31 \pm 0.02)$. This result quite differs from the results of previous study by Hahn and Rim done by computerized tomography $(\mathrm{CT})$ in which range varied from 0.19 to 0.39 but confirmed the average which was $(0.31 \pm 0.04)$. It was suggested that a maximum frontal diameter greater than $40 \%$ or less than $18 \%$ of the brain width on the corresponding levels are highly suspicious of abnormal ventricles. In our case maximum value and minimum values were $35 \%$ and $25 \%$ of the brain width and increase in the frontal horn ratio was very marginal. The study of large sample size was done in Korea by Park et al. (1990) found comparable frontal horn index of (0.3 \pm 0.03 ) and they described the correlation with increasing age. The frontal horn index in present study was matched with the Park et al. (1990) study without any significant difference observed.

Another study done by Cala et al. (1981) found ventriculo - internal cranial ratio (frontal horn ratio) of $(0.31 \pm 0.08)$ in female and $(0.33 \pm 0.06)$ in male. Cala states that normal data on the dimension of the ventricular system are required for the investigation of neurological diseases. The study was conducted to discover how much dilation of cerebrospinal fluid containing space occurs with advancing age up to 40 years. The differences between the genders were not statistically significant. Present female ratio was matched while the male ratio was quite less than Cala et al. (1981) study. Further, Soininem et al. (1982) studied frontal horn ratio with no neurological diseases above 65 years with mean age of $75 \pm 7$ years. The study found the mean frontal horn ratio of $(0.32 \pm$ 0.04 ) which was similar with present study.

\section{Third ventricle: Transverse dimension}

Table 6. Comparison of transverse dimension of third ventricle with previous study

\begin{tabular}{|l|c|c|l|c|c|}
\hline Worker & Method & Subjects & Gender & Mean & S.D. \\
\hline Gawler & CT & 78 & M/F & 4.6 & 2.7 \\
\hline Duffner & MRI & 30 & M/F & 3.3 & 1.8 \\
\hline D'Souza & CT & 1000 & M/F & $4.5 / 3.9$ & $2.9 / 1.7$ \\
\hline Singh & CT & 358 & M/F & $3.47 / 3.31$ & $1.07 / 0.94$ \\
\hline Satapara & MRI & 63 & M/F & $5.2 / 5.2$ & $2.3 / 2.5$ \\
\hline Present & MRI & 150 & M/F & $4.7 / 4.4$ & $1.0 / 1.1$ \\
\hline
\end{tabular}

D'Souza and Natekar (2007) studied morphometry of ventricular system for the large sample size found the width of third ventricle in male and female were $(4.5 \pm$ $2.9) \mathrm{mm}$ and $(3.9 \pm 1.7) \mathrm{mm}$. In case of current study, male width $(4.7 \pm 1.0) \mathrm{mm}, 95 \%$ CI $(4.5-5.0)$ was observed to be comparable whereas female width $(4.4 \pm$ $1.1) \mathrm{mm}, 95 \% \mathrm{CI}(4.2$ - 4.6) seems higher than observed by D'Souza and Nateker (2007). Singh et al. (2014) found the width of third ventricle $(3.47 \pm 1.07) \mathrm{mm}, 95 \%$ CI $(3.32-3.62)$ in male and $(3.31 \pm 0.94) \mathrm{mm}, 95 \% \mathrm{CI}$ (3.16 - 3.46) in female. In case of present study width was observed to be greater than Singh study in both case of male and female. The width was observed to be greater in male than female and was not differs significantly as in case of Singh et al. (2014) studies. The study done by the Duffner et al. (2003) measured in coronal plane found the overall mean of $(3.3 \pm 1.8) \mathrm{mm}$. The present study was done in axial plane which indicates overall mean of $(4.6 \pm 1.0) \mathrm{mm}, 95 \% \mathrm{CI}(4.4$ - 4.7) greater than observed by Duffner et al. (2003).
Recently, studies done by Satapara et al. (2014) by MRI found $(5.2 \pm 2.3) \mathrm{mm}$ and $(5.2 \pm 2.3) \mathrm{mm}$ for male and female respectively with overall mean $(5.2 \pm 1.4) \mathrm{mm}$. In Satapara et al. (2003) study width of third ventricle increases as age increases which was statistically significant. He also indicates that difference in observed value with other similar studies was due to the difference in method and population. This study shows that third ventricle width increases slightly with no statistically significant differences.

Fourth ventricle: Anterior-posterior dimension

Table 7. Comparison of anterior - posterior dimension of fourth ventricle with previous study

\begin{tabular}{|l|l|c|l|c|c|}
\hline Worker & Method & Subjects & Gender & Mean & S.D. \\
\hline Gawler & CT & 78 & M/F & 10.8 & - \\
\hline D'Souza & CT & 1000 & $\mathrm{M} / \mathrm{F}$ & $11.8 / 11.1$ & $2.7 / 2.4$ \\
\hline Singh & CT & 358 & $\mathrm{M} / \mathrm{F}$ & $12.18 / 12.13$ & $1.54 / 1.41$ \\
\hline Present & MRI & 150 & $\mathrm{M} / \mathrm{F}$ & $9.9 / 9.4$ & $1.1 / 1.1$ \\
\hline
\end{tabular}


Fourth ventricle: Width

Table 8. Comparison of width of fourth ventricle with previous study.

\begin{tabular}{|l|c|c|c|c|c|}
\hline Worker & Method & Subjects & Gender & Mean & S.D. \\
\hline Duffner & MRI & 30 & M/F & 12.5 & 1.7 \\
\hline D'Souza & CT & 1000 & M/F & $13.1 / 12.1$ & $2.3 / 2.2$ \\
\hline Singh & CT & 358 & M/F & $11.07 / 11.05$ & $1.54 / 1.31$ \\
\hline Present & MRI & 150 & M/F & $12.3 / 11.7$ & $1.2 / 1.2$ \\
\hline
\end{tabular}

Study by D'Souza and Natekar (2007) found the height of the fourth ventricle in male $(11.8 \pm 0.027) \mathrm{mm}, 95 \% \mathrm{CI}$ $(6.5-17.1)$ and female $(11.1 \pm 0.024) \mathrm{mm}, 95 \% \mathrm{CI}(6.5$ - 15.8). Similarly, width of fourth ventricle were (13.1 $\pm 0.023) \mathrm{mm}, 95 \% \mathrm{CI}(8.5-17.7)$ and $(12.1 \pm 0.022)$ $\mathrm{mm}, 95 \% \mathrm{CI}(7.9$ - 16.4) in male and female respectively. In current study, mean anterior - posterior dimension (height) was observed to be $(9.9 \pm 1.1) \mathrm{mm}, 95 \% \mathrm{CI}(9.6$ - 10.1) and (9.4 \pm 1.1$) \mathrm{mm}, 95 \% \mathrm{CI}(9.2-9.7)$ in male and female respectively which was lower than the study done by D'Souza and Natekar (2007). Similarly width is (12.3 $\pm 1.2) \mathrm{mm}, 95 \% \mathrm{CI}(12.0-12.6)$ and $(11.7 \pm 1.2) \mathrm{mm}$, $95 \%$ CI (11.4 - 12.0) in male and female respectively. This value was similar with them. Also width of the fourth ventricle was observed to be large than its height in both male and female as found in their study. Singh et al. (2014) recently studied the fourth ventricle size and found height $(12.18 \pm 1.54) \mathrm{mm}, 95 \% \mathrm{CI}(11.97$ - 12.39) and $(12.13 \pm 1.41) \mathrm{mm}, 95 \% \mathrm{CI}(11.91-12.36)$ and width $(11.07 \pm 1.54) \mathrm{mm}, 95 \% \mathrm{CI}(10.85-11.28)$ and $(11.05 \pm$ 1.31) $\mathrm{mm}, 95 \% \mathrm{CI}(10.84-11.26)$ in male and female respectively. The values were not differed statistically in case of male and female. But in the present study anterior - posterior dimension (height) was lower and width was higher than Singh et al. (2014) study. These values were differed statistically.

Studies by Gawler et al. (1976) revealed that the greatest distance between the roof and floor of the fourth ventricle was less than $12 \mathrm{~mm}$ with a mean of $10.8 \mathrm{~mm}$ which was comparable with anterior - posterior dimension of present study. Further, studies by Duffner et al. (2003) measured the width of fourth ventricle in sagittal plane with a mean of $(12.5 \pm 1.7) \mathrm{mm}$ which was comparable with present calculation of width with overall mean of $(12.0 \pm 1.3) \mathrm{mm}$.

\section{CONCLUSION}

The human brain complication makes it more interesting subject for research. With ageing human brain structural changes are considered normal. To explore the changes in the human brain, it is important to monitor the changes in some internal organs which are sensitive enough to the abnormalities in the brain. Thus, we have measured the sizes of the brain ventricles which are detective to the MRI technique.

These measurements had the clinical correlation in diagnosis, treatment and surgical intervention. Analysis of ventricles measurements is important for evaluating changes due to growth and ageing. Further, these measurements can be used in diagnosis of some diseases like Schizophrenia and Alzheimer's and surgical intervention like endoscopic neurosurgery. The ranges of ventricular dimension were presented for the baseline for the future investigation which tends to maintain standard dimensions. The measurement of ventricular dimensions was observed to be differed statistically between male and female except transverse dimension of third ventricle and was observed to be greater in male than in female in all cases. MRI imaging studies are clearly required to test our hypothesis and to clarify the functional significance of difference in ventricular size.

\section{REFEREN ES}

Asthari, M., Zito, J.L., Gold, B.I., Lieberman, J.A., Borenstein, M.T. and Herman, P.G. 1990. Computerized volume measurement of brain structure. Investigative Radiology 25: 798-805.

Aziz, A., Hu Qing, M., and Nowinski W.L. 2004. Morphometric analysis of cerebral ventricular system from MR images. Medical Imaging, International Society for Optics and Photonics 5369: 574-582.

Cala, L.A., Thickbroom, G.W., Black, J.L., Collins, D.W.K. and Mastagllia, F.L. 1981. Brain density and cerebrospinal fluid space size: CT of normal volunteers. American Journal of Neuroradiology 2: 41-47.

D'Souzae Dias, M. and Natekar, P.E. 2007. Morphometric study of the ventricular system of Brain by Computerised Tomography. Journal of the Anatomical Society of India 56: 19-24. 
Duffner, F., Schiffbaur, H., Glemser, D., Skalei, M. and Freudenstein, D. 2003. Anatomy of the cerebral ventricular system for endoscopic neurosurgery: a magnetic resonance study. Acta neurochirurgica 145: 359-368.

Evans, W.A. 1942. An encephalographic ratio for estimating ventricular enlargement and cerebral atrophy. Archives of Neurology and Psychiatry 47: 931-937.

Gawler, J., duBoulay, G.H., Bull, J.H.D. and Marshall, J. 1976. Computerised tomography (the EMI Scanner): a comparision with pneumoencehalography and ventriculography. Journal of Neurology, Neurosurgery and Psychiatry 39: 203- 211.

Hahn, F.J.Y. and Rim, K. 1976. Frontal ventricular dimensions on normal computed tomography. American Journal of Roentgenology 126: 593596.

Haug, G. 1977. Age and sex dependence of the size of normal ventricles on computed tomography. Neuroradiology 14: 201-204.

Park, C.O., Chae, K.B., Lee, S.D., Kim, Y. and Ha, Y.S. 1990. The study in frontal ventricular measurement and correlation between cerebroventricular index and cephalic index on normal computed tomography. Journal of Korean Neurosurgical Society 19: 608-624.

Riegel, T., Freudenstein, D., Duffner, F., Hellwig, D., Bartel, V. and Bertalany, H. 2002. Novel multipurpose bipolar instrument for endoscopic neurosurgery. Neurosurgery 51: 270-274.
Roberts, M.A. and Caird, F.I. 1976. Computerized tomography and intellectual impairment in the elderly. Journal of neurology, neurosurgery and psychiatry 39: 986-989.

Rushton, J.P. and Ankey, C.D. 1996. Brain size and cognitive ability: Correlation with age, sex, social class and race. Psychonomic Bulletin and Review 3: 21-36.

Satapara, V.K., Patel, M.M., Rathava, J.K., Trivedi, P.N., Kukadiya, U.C., Gohil, D.V. and Singel, T.C. 2014. Morphometry of width of third ventricle of brain by luminal cast Plastination and MRI. International Journal 2: 837-842.

Schochet, S.S. 1998. Neuropathology of aging. Neurologic clinics 16: 569-580.

Singh, B. R., Gajbe, U., Agrawal, A., Reddy, A. and Bhartiya, S. 2014. Ventricles of brain: A morphometric study by computerized tomography. International Journal of Medical Research and Health Science 3: 381-387.

Soininen, M., Puranen, M. and Reikkinen, P.J. 1982. Computed tomography findings in senile dementia and normal aging. Journal of Neurology; Neurosurgery and Psychiatry 45: 50-54

Srijit, D. and Shipra, P. 2006. Anatomical study of anomalous posterior horn of lateral ventricle of brain and its clinical significance. Bratislavske Lekarske Listy 108: 422-424.

Zaidi, Z.F. 2010. Gender differences in human brain: a review. The Open Anatomy Journal 2: 37-55. 